\title{
Study on radon dispersion modes from the U-mine disposal sites at Žirovski Vrh (Slovenia)
}

\author{
M.J. Križman ${ }^{1}$, J.E. Peter ${ }^{2}$ and J. Rojc ${ }^{3}$ \\ ${ }^{1}$ Slovenian Nuclear Safety Administration, 1000 Ljubljana, Slovenia \\ ${ }^{2}$ Federal Office for Radiation Protection, 85764 Oberschleissheim, Germany \\ ${ }^{3}$ Žirovski Vrh Mine, 4224 Gorenja vas, Slovenia
}

\begin{abstract}
Long-term averages of outdoor radon levels give no information on time and spatial behaviour of dispersed radon that exhales from U-mine disposal sites. A comprehensive network of automatic stations for continuous measurements of short-lived radon decay products was installed in the early nineties at the Žirovski Vrh uranium mine. The instruments were positioned at key locations, on-site and off-site uranium mining area, and recorded EEC levels, alpha spectra, and local temperatures, all at least on hourly basis. Analyses of simultaneous records of EEC time series from several locations and analyses of corresponding alpha spectra gave more detailed information on characteristic patterns of radon behaviour and its dispersion from the sites under study. The identified modes of radon dispersion, depending on the presence and type of temperature inversion and the related major findings on the radon impact to the environment are shortly presented.
\end{abstract}

\section{INTRODUCTION}

Long-term measurements of outdoor radon with passive detectors are generally used for the determination of the environmental levels and the impact of radon sources, among them those originating from uranium mine facilities. Average radon concentrations are input data for exposure assessment of the public but do not reveal any information on actual temporal and spatial behaviour of the released radon. In case of the Žirovski Vrh mine, the only Slovenian uranium mine, this goal was realised through a network of automatic radon stations installed mostly within the affected area.

The aim of this paper is to present the main findings on actual modes of radon dispersion from the mine disposal sites to the environment.

Uranium mining and milling at Žirovski Vrh were carried out from 1985 to 1990. The site area is located mainly in a deep valley, surrounded by the hills of relative heights of up to 400-600 metres and all disposal sites are situated on the hill slopes. Frequent and strong temperature inversions (about $55 \%$ of the time of a year, temperature gradient mostly $0.02-0.03 \mathrm{~K} / \mathrm{m}$ ) are important characteristics of the site. During the operational period 452 tonnes of yellow cake were produced from the ore with a moderate content of uranium $\left(840 \mathrm{~g}\right.$ /tonne $\left.\mathrm{U}_{3} \mathrm{O}_{8}\right)$. After cessation, the underground mine was closed and not ventilated any more. Several disposal sites with bare areas remained, among them a large waste rock pile and a large tailings pile. Each of them has an area of 4 hectares and both were significant sources of radon, $2 \mathrm{TBq} / \mathrm{y}$ and $4 \mathrm{TBq} / \mathrm{y}$ respectively. The restoration of the uranium mine disposal sites started in the recent years and has been approaching the final phase. As for the environmental impact of the Žirovski Vrh uranium mine, radon was found to be the most important exposure pathway since it contributes up to $80 \%$ of the total effective dose to the public or $0.20 \mathrm{mSv}$ per year [1].

\section{INSTRUMENTS AND METHODS}

A special device for continuous measurements of radon decay products was originally designed by the GSF Institute (Neuherberg, Germany). It consisted of an air sampler, a PIPS detector with an 
area of $300 \mathrm{~mm}^{2}$ connected to a 256 channel analyser, and a data storage unit (Figure 1). Air was pumped through a PTFE filter with $25 \mathrm{~mm}$ diameter and $1.2 \mu \mathrm{m}$ pore size with a flow-rate of $120 \mathrm{~L} / \mathrm{min}$. The instruments measured equilibrium equivalent radon concentrations (EEC), alpha spectra, local temperatures and air flow rate through the filter, all at least on hourly basis [2]. The data files were recorded and stored locally and manually transferred to the database later on.

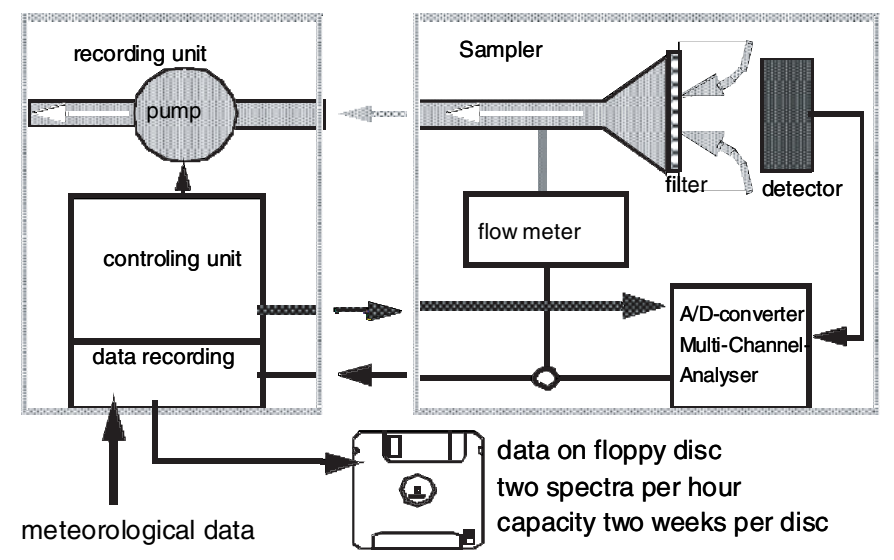

Figure 1. Schematic outline of the automatic radon progeny device (GSF Neuherberg, Germany).

A comprehensive network for continuous measurements of short-lived radon decay products was set up in the early nineties in the frame of the Slovenian-Bavarian bilateral research and technical collaboration [3]. Fourteen automatic stations were installed at key locations, on-site uranium mining area (within disposal sites and on their perimeters), and off-site, including settlements along the affected valleys and a reference point (Figure 2).

A methodology for determination of radon dispersion modes was based primarily on the evaluation of magnitudes of EEC versus different locations, the evaluation of their time dependence diagrams and, in case of a temperature inversion, on estimating the inversion height and the temperature gradient.

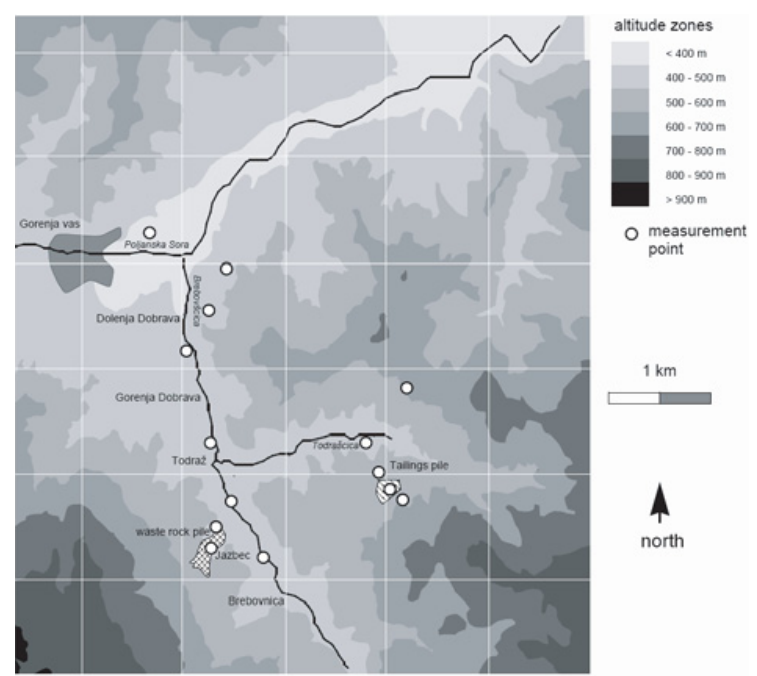

Figure 2. Map of the Žirovski Vrh uranium mine site with indicated locations of radon progeny measurement. 
Radon was used here as a matter of research and also as a natural tracer. Time of development, duration and decomposition of temperature inversions were analysed from the shapes of concentration curves and from temperature data. A comparison of temperature-time diagrams and concentration-time diagrams was used to ascertain if an ascending or descending air flow (enriched with radon) moves from the disposal site further to the environment.

Simultaneous records of the EEC time series from several locations and corresponding alpha spectra can give additional information on radon dispersion. Equilibrium factor and an approximate age of radon were estimated, being used as a proof for the presence of "young" radon of mine origin. By comparing spectra recorded at locations with different heights, the directions of radon flow were additionally confirmed. Spectra of thoron daughters can be used as an indication of local air turbulence and can give an information on natural levels of radon within the affected area.

\section{RESULTS AND DISCUSSION}

Radon dispersion to the environment is related to the local meteorology and topography and is effectuated by the atmospheric turbulence and diffusion. The results of the radon network clearly identified numerous and various radon transport pathways from the disposal sites to the surrounding environment.

During unstable windy weather the impact of mine radon is very weak and cannot even be detected. Under stagnant synoptic conditions, vertical mixing of radon is the major process for restoring low concentrations of radon and its short-lived progeny during the day, due to a dilution with clean air from above the mixing layer. When boundary layer stabilises during late afternoon and early evening over the radon source area, the exhaled radon is trapped in the inversion layer. High radon concentrations and therefore considerable mine contributions of radon were measured.

The term "radon" in further text has the meaning as "radon that originates from the disposal site". EEC figures quoted in the text in the parentheses indicate the maximum values in a daily cycle. Values of radon equilibrium factor are estimated on hourly measurements.

\subsection{Radon dispersion modes on the tailings pile}

The disposal site with hydrometalurgical tailings is located at elevated position, on the slope of the Boršt hill $(535-575 \mathrm{~m}), 100$ metres above the lateral valley. For the most part of the time its position is above the average height of inversion layer (around $500 \mathrm{~m}$ ) and a low impact is expected, however, depending very much on the existence of various temperature inversion types. Some typical cases of radon dispersion are presented, appearing repeatedly in a particular season.

(a) During the day and in late afternoon when a growing inversion layer has not reached the height of disposal site uphill, radon concentrations are pretty low because radon is strongly dispersed. Low EEC concentrations were measured elsewhere, on the site and upwards and downwards the slope $\left(<20 \mathrm{~Bq} \mathrm{~m}^{-3}\right)$ and rarely up to $30 \mathrm{~Bq} \mathrm{~m}^{-3}$ in the valley. Efficient mixing causes that there is no radon transport to the valley and therefore no influence to the reference group could be attributable.

(b) In stable weather conditions, when the inversion layer is established at the height of the disposal site plateau, vertical ventilation into the free troposphere is reduced. The results show that a continuous and moderate air flow with radon from the disposal site downwards the slope was established, thus enhancing concentrations in the valley. Concentrations prevailing on the site area and downwards are elevated $\left(60 \mathrm{~Bq} \mathrm{~m}^{-3}\right)$ and are typically equal to those at the valley $\left(65 \mathrm{~Bq} \mathrm{~m}^{-3}\right)$ where radon tends to accumulate. A low equilibrium factor of radon was measured in the radon flow downstream the site: $F=0.2$ in summer and slightly higher in winter: $F=0.3$. The EEC levels at locations above the temperature inversion are much lower $\left(38 \mathrm{~Bq} \mathrm{~m}^{-3}\right)$, indicating only a weak impact of radon from the disposal site. 
(c) In case when the upper boundary of inversion layer extends over the height of the disposal plateau, the concentrations on the site and around it are uniform as measured in a typical case: those upward the tailings pile $\left(50 \mathrm{~Bq} \mathrm{~m}^{-3}\right)$ are equal to those observed downward the pile and in the valley $\left(52 \mathrm{~Bq} \mathrm{~m}^{-3}\right.$ and $50 \mathrm{~Bq} \mathrm{~m}^{-3}$ respectively) indicating that radon is accumulated and well mixed within the layer. The EEC values on the disposal plateau are slightly enhanced $\left(65 \mathrm{~Bq} \mathrm{~m}^{-3}\right)$. Equilibrium factors are relatively high: on the site plateau $\mathrm{F}=0.45$, below the site $\mathrm{F}=0.35$ and in the valley up to 0.7 . Such situations are typical for very stable winter weather and indicate a considerable radon impact to the valley. High EEC values were measured within the disposal plateau in the morning just before the inversion layer decomposition, occasionally in the form of sharp peaks $\left(60-80 \mathrm{~Bq} \mathrm{~m}^{-3}\right)$ of duration of some hours (Figure 3).

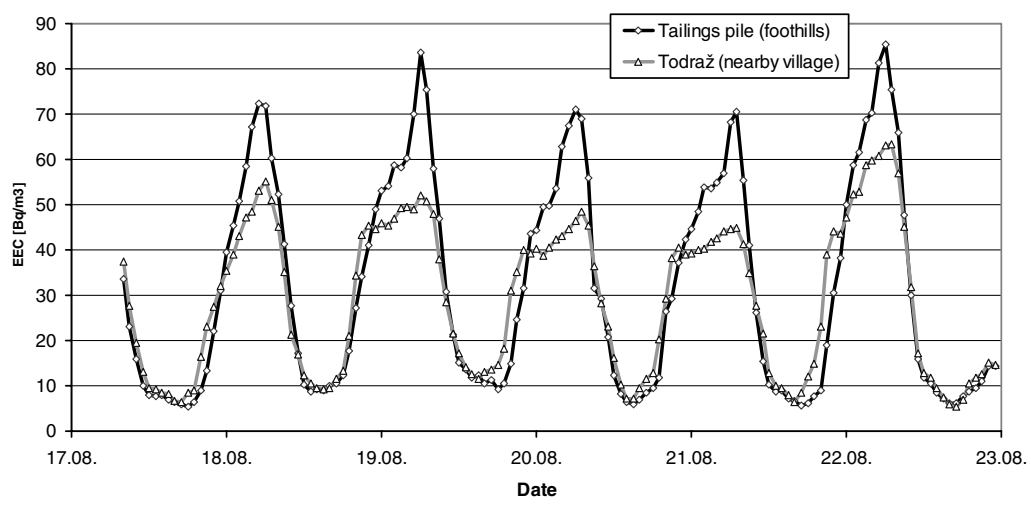

Figure 3. Example for radon dispersion from tailings pile, located at the slope of a hill: sharp peaks of EEC at the foothill of the pile (dark curve) were recorded in summer mornings, before decomposition of an inversion layer; maximum EEC levels in the valley below (bright curve) were evidently lower.

(d) In case of the elevated inversion layer, when the disposal site uphill on the slope is captured within it, radon can be horizontally transported from the site $\left(\mathrm{EEC} 65 \mathrm{~Bq} \mathrm{~m}^{-3}\right)$ by laminar air flow, crossing above the valley to the opposite slope of the hill and can affect the distant settlements on this slope. Cases were found when EEC concentrations on the opposite side of the valley were slightly higher $\left(50 \mathrm{~Bq} \mathrm{~m}^{-3}\right)$ than those in the valleys below $\left(35-45 \mathrm{~Bq} \mathrm{~m}^{-3}\right)$. Radon equilibrium factor at the opposite slope was apparently lower $(\mathrm{F}=0.55)$ than that in the valley $(\mathrm{F}=0.75)$. The radon impact to the opposite side can be estimated as moderate but anyhow higher than to the valley below the disposal site.

(e) Up-slope air flows are generated during the day when air is warmed by the land surface and moves up the slope. Exhaling radon from the disposal site is consequently transported upwards the hill. EEC values, measured during the day can be significantly higher upwards the disposal site than those measured downwards: almost $70 \mathrm{~Bq} \mathrm{~m}^{-3}$ versus $35-40 \mathrm{~Bq} \mathrm{~m}^{-3}$ (can be named as "radon inversion" because concentrations within the certain area are increasing with the height). Equilibrium factor upwards the disposal site is higher $(\mathrm{F}=0.4)$ than in previous cases of descending radon.

\subsection{Radon dispersion modes on the mine waste rock pile}

The mine waste rock pile with 1.5 million tonnes of material is situated over a former ravine of the Jazbec stream, extending from the bottom of the main valley uphill (425-495 m), with the plateau at the height of 70 metres. For the most part of time it is positioned under an average height of inversion layer, so a higher impact to the environment is expected, although that uranium grade in waste rock is of the order of $50 \mathrm{~g} \mathrm{U} /$ tonne. 
(a) By late winter afternoon when strong inversion layer starts growing in the valley, EEC values at the foothill of the pile are rapidly and essentially enhanced (up to $60-70 \mathrm{~Bq} \mathrm{~m}^{-3}$ ), while in the middle of the pile slope and on its plateau the values are much lower, 45 and $20 \mathrm{~Bq} \mathrm{~m}^{-3}$ respectively. Radon mixing above the inversion layer is very effective, the impact to the settled locations in the valley is small $\left(<20 \mathrm{~Bq} \mathrm{~m}^{-3}\right)$.

(b) In winter time when inversion layer extends above the height of the disposal plateau, radon from the pile area is dispersed uniformly within the inversion layer. Maximum concentrations on the pile are rather high $\left(70-100 \mathrm{~Bq} \mathrm{~m}^{-3}\right)$ and equal to those observed downstream $\left(75 \mathrm{~Bq} \mathrm{~m}^{-3}\right)$ and at the foothills of the valley $\left(70 \mathrm{~Bq} \mathrm{~m}^{-3}\right)$. Equilibrium factor on the bare mine waste pile area is about $\mathrm{F}=0.3$, at the foothills about 0.4 and farther in the valley about 0.6 . Radon impact from the pile to the environment is high also due to long lasting inversions, frequently all the day, especially after several days of stagnant air.

(c) In summer time in late afternoons when temperature inversion is still in its early phase, time series of EEC at the pile foothills showed sharp peaks with the duration of 3-6hours, usually with the observed maximum values, extending over $200 \mathrm{~Bq} \mathrm{~m}^{-3}$ and with radon equilibrium factor of $\mathrm{F}=0.2-0.3$ (Figure 4). This phenomenon revealed an additional radon source, namely radon flow coming from the outlet of the underground pile drainage, with ${ }^{222} \mathrm{Rn}$ concentrations of $20 \mathrm{kBq} \mathrm{m}^{-3}$ and EEC of $1.6-2 \mathrm{kBq} \mathrm{m}^{-3}$. Figures of equilibrium factor are quite in agreement with the field measurements of Bernhard et al. [4] and Raviart et al. [5]. These EEC peaks can be followed at greater distances downstream the valley, mostly as sharp increases of EEC superimposed to the normal rise of concentrations in late afternoons. Typical rapid increases of $30-50 \mathrm{~Bq} \mathrm{~m}^{-3} / \mathrm{h}$ on the site and in the very vicinity were recorded. In the affected environment (at nearby settlements) this rate is $5-10 \mathrm{~Bq} \mathrm{~m}^{-3} / \mathrm{h}$ and only $2-4 \mathrm{~Bq} \mathrm{~m}^{-3} / \mathrm{h}$ was found at the distant reference point (as for natural background).

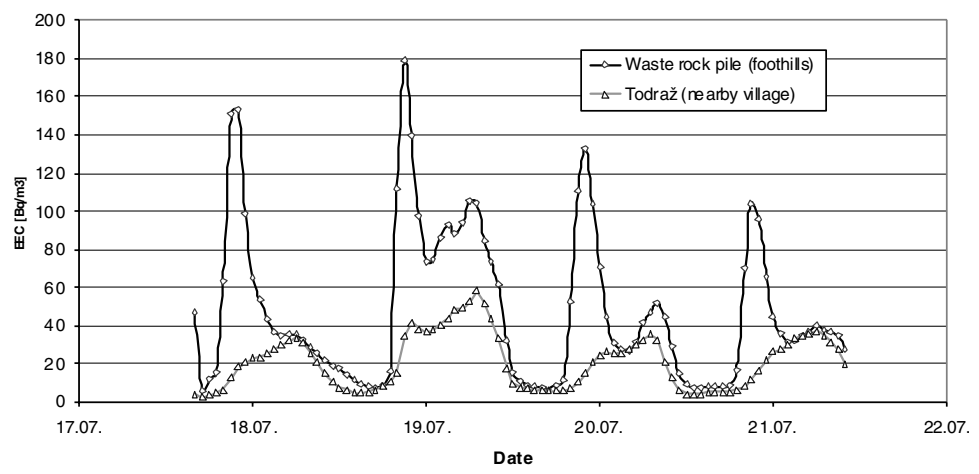

Figure 4. Example for radon dispersion from the mine waste rock pile: high peak values of EEC at the foothill of the pile (dark curve) in comparison with the levels recorded farther in the valley (bright curve), as recorded in summer late afternoons with a rising inversion layer.

(d) Up-slope radon dispersion from waste rock pile was measured for a short time in the recent years with an active radon device (Alphaguard) during the summer period. A raise of radon concentrations upward the settled sideward slope was not found, due to the well ventilated area.

Typical annual averages of EEC in the main valley were of the magnitude of $16 \mathrm{~Bq} \mathrm{~m}^{-3}$, involving together a mine contribution and natural background [3]. Within the disposal areas, peak levels of ECC outdoors likely exceed $200 \mathrm{~Bq} \mathrm{~m}^{-3}$ while at the settlements in the valley, that are $0.5-2.5 \mathrm{~km}^{\text {distant, }}$ maxima over $60 \mathrm{~Bq} \mathrm{~m}^{-3}$ are not usual and have been recorded only in winter time during stable weather conditions. During the inversions radon is channelled downwards the valley and its concentrations quite slowly decrease with distance. Average radon ${ }^{222} \mathrm{Rn}$ concentrations in both valleys are $25-30 \mathrm{~Bq} \mathrm{~m}^{-3}$ and about a quarter of this value is contributed by the U-mine sources [1]. 
The patterns of radon dispersion were studied with the emphasis on radon transfer to the populated areas, with the final aim to estimate the public exposure. Radiological evaluation of particular radon events (such as sharp peaks of EEC in daily diagram at specific locations, showed that a member of the public staying at his work near the fence of the mining area for some hours, receives the effective dose up to $5 \mu \mathrm{Sv}$ per single event. This is a great deal more than the total annual exposure of an individual who lives in the vicinity of a nuclear power plant $(\sim 1 \mu \mathrm{Sv}$ per year).

\section{CONCLUSIONS}

The results of the radon short-lived daughter network at Žirovski Vrh definitively showed that radon impact on the environment in general is not uniform and constant, neither in time nor in space and can be classified into different dispersion modes. The latter depend mainly on meteorological conditions and appear in different ways, mostly in time pulses of high concentrations and in steady-state flows of enhanced radon levels with a low equilibrium factor. The ways of the impact and their intensities are considerably changed from one season to another, depending on temperature, duration of inversions, and winds. At low-level ground inversion radon from the elevated source has no influence to the settlements in the valley; the highest EEC values and therefore the highest impact appear in cases when the disposal site is below the upper boundary, especially during winter. Horizontal movements (traversing the valley) and up-slope movements of intensive radon flow from the disposal sites have not been frequently observed.

Short-term radon peaks exceeding the natural background for several times and sharp time rises of EEC are typical for the warm period. Inversely, steady-state radon flows are characteristic of cold seasons. The EEC maxima depend on atmospheric stability and the distance from the source. At growing inversion layer, concentrations near the radon source are increasing essentially faster than in the unaffected natural environment. The EEC time series at high elevations differ from those recorded in the valley: late appearance and early decomposition of inversions result in lower average values.

Based on the results of the radon network at Žirovski Vrh, the patterns of radon dispersion from the source to the environment and of radon impact to the environment can be predictable elsewhere [4, 6], particularly in cases with a similar topographic situation.

\section{References}

[1] M. Križman and P. Stegnar, Radiation Protection Dosimetry 45 (1992) 723-728.

[2] J.E. Peter and M. Križman, Long-term measurements of radon and its decay products in the environment by continuous $\alpha$-spectrometry (in German), in Proceedings of $26^{\text {th }}$ Annual meeting of Fachverbandes fur Strahlenschutz - "Strahlenschutz: Physik und Messtechnik", Karlsruhe, 24-26 May, 1994, edited by W. Kölzer and R. Maushart (TUV Reinland, Kòln, 1994), pp. 792-797.

[3] J. Peter, Environmental Impact of the Uranium Mine (in German), GSF End Report, published by Bayerisches StMLU, München, 1994, pp. 1-67.

[4] S. Bernhard, C. Gibaud, J.F. Pineau, F. Sarradin and Y. Vauzelle, Time integrated measurements of potential alpha energy (PAE) due to short-lived decay products of radon 220 and 222 in the environment, in Proceedings of the $9^{\text {th }}$ International Congress of the International Radiation Protection Association, Vienna, 14-19 April 1996, (Vol. 2, IRPA, Seibersdorf 1996), pp. 144-146.

[5] S. Raviart, P. Richon, D. Haristoy, M.C. Robé, Y. Belot, M. Kümmel, C. Düshe W. Ullman, Environment International 2 (1996) S279-S286.

[6] P. Martin, S. Tims, B. Ryan and A. Böllhofer, Journal of Environ. Radioactivity 76 (2004) 35-49. 